\title{
7,8-Dihydroxyflavone protects human keratinocytes against oxidative stress-induced cell damage via the ERK and PI3K/Akt-mediated Nrf2/HO-1 signaling pathways
}

\author{
MIN JU RYU ${ }^{1}$, KYOUNG AH KANG ${ }^{2}$, MEI JING PIAO ${ }^{2}$, KI CHEON KIM ${ }^{2}$, JIAN ZHENG ${ }^{2}$, \\ CHENG WEN YAO $^{2}$, JI WON CHA ${ }^{2}$, HA SOOK CHUNG ${ }^{1}$, SANG CHEOL KIM ${ }^{3}$, \\ EUNSUN JUNG ${ }^{3}$, DEOKHOON PARK $^{3}$, SUNGWOOK CHAE $^{4}$ and JIN WON HYUN ${ }^{2}$
}

\begin{abstract}
${ }^{1}$ Food and Nutrition, Duksung Women's University, Seoul 132-714; ${ }^{2}$ School of Medicine and Institute for Nuclear Science and Technology, Jeju National University, Jeju 690-756; ${ }^{3}$ Biospectrum Life Science Institute, Seongnam, Gyunggi Do 442-13;

${ }^{4}$ Aging Research Center, Korea Institute of Oriental Medicine, Daejeon 305-811, Republic of Korea
\end{abstract}

Received September 23, 2013; Accepted January 30, 2014

DOI: 10.3892/ijmm.2014.1643

\begin{abstract}
This study investigated the effect of 7,8-dihydroxyflavone (DHF) on the expression and activity of heme oxygenase-1 (HO-1), an enzyme with potent antioxidant properties, as well as the molecular mechanisms involved. DHF markedly upregulated HO-1 mRNA and protein expression in human keratinocytes (HaCaT cells), resulting in increased HO-1 activity. DHF also increased the protein level of transcription factor nuclear factor erythroid 2-related factor 2 (Nrf2), which regulates $\mathrm{HO}-1$ expression by binding to the antioxidant response element (ARE) within the HO-1 gene promoter, in a time-dependent manner. Moreover, DHF decreased the expression of Kelch-like ECH-associated protein 1, a repressor of Nrf2 activity, and induced the translocation of Nrf2 from the cytosol into the nucleus, thereby allowing its association with the ARE site. DHF activated extracellular-regulated kinase (ERK) and protein kinase $\mathrm{B}$ (PKB, Akt) in keratinocytes, while the ERK and Akt inhibitors attenuated DHF-enhanced Nrf2 and HO-1 expression. DHF also protected the keratinocytes against hydrogen peroxideand ultraviolet B-induced oxidative damage, while HO-1, ERK and Akt inhibitors markedly suppressed DHF-mediated cytoprotection. Taken together, the results suggested that DHF activates ERK- and Akt-Nrf2 signaling cascades in HaCaT cells, leading to the upregulation of HO-1 and cytoprotection against oxidative stress.
\end{abstract}

Correspondence to: Professor Jin Won Hyun, School of Medicine and Institute for Nuclear Science and Technology, Jeju National University, 102 Jejudaehakro, Jeju 690-756, Republic of Korea E-mail: jinwonh@jejunu.ac.kr

Key words: cytoprotection, 7,8-dihydroxyflavone, heme oxygenase-1, nuclear factor erythroid 2-related factor 2, oxidative stress, human keratinocytes

\section{Introduction}

Reactive oxygen species (ROS) [e.g., superoxide anions, hydroxyl radicals, and hydrogen peroxide $\left.\left(\mathrm{H}_{2} \mathrm{O}_{2}\right)\right]$ can harm cellular proteins, lipids and DNA $(1,2)$. Long-term effects of oxidative damage to the skin include premature aging, cancer and inflammation (3-5).

Heme oxygenase-1 (HO-1, one of three heme oxygenase isoforms) is an extensively studied phase II enzyme that is essential for the rate-limiting step of heme catabolism. Heme catabolism leads to the formation of carbon monoxide, ferrous iron $\left(\mathrm{Fe}^{2+}\right)$ and biliverdin, which is converted into bilirubin by biliverdin reductase (6). The end products of heme catabolism exert antioxidant effects by neutralizing intracellular ROS $(7,8)$. Thus, HO-1 demonstrates potent cytoprotective properties against oxidative damage (9-11), and the induction of its expression increases cellular resistance to oxidative stress.

HO-1 expression is primarily regulated at the transcriptional level and is induced by the transcription factor nuclear factor erythroid 2-related factor 2 (Nrf2) $(12,13)$. Under basal conditions, Nrf2 is constitutively docked to Kelch-like ECH-associated protein 1 (Keap1) in the cytoplasm, culminating in the ubiquitination and proteosomal degradation of Nrf2 (14). However, Keap1 is oxidized under conditions of electrophilic stress, which blocks Nrf2 degradation and allows Nrf2 phosphorylation, nuclear translocation, and association with the antioxidant response element (ARE) within the HO-1 gene promoter region. The net result of ARE binding by Nrf2 is the activation of multiple antioxidant genes, including HO-1 (15).

Similar to Keap1, extracellular signal-regulated kinase (ERK) and protein kinase $\mathrm{B}$ (PKB, Akt) are involved in the transduction of various signals from the cell surface to the nucleus. Both of their signaling pathways are associated with the modulation of ARE-driven gene expression via Nrf2 activation $(16,17)$.

The polyphenolic compound 7,8-dihydroxyflavone (DHF) is a member of the flavonoid family with antioxidant properties (18-21). 
In a previous study, we reported that DHF protected cells against oxidative stress-induced genotoxicity by scavenging intracellular ROS and enhancing Akt activity (22).

In the present study, we investigated the cytoprotective mechanisms of DHF against oxidative stress-induced cell damage in human keratinocytes with respect to its stimulatory effects on HO-1 expression and activity. We also investigated the molecular mechanisms involved in DHF-mediated cytoprotection and HO-1 induction, with a particular focus on ERK- and Akt-Nrf2 signaling cascades.

\section{Materials and methods}

Materials. [3-(4,5-Dimethylthiazol-2-yl)-2,5-diphenyltetrazolium] bromide (MTT) and zinc protoporphyrin (ZnPP) were purchased from Sigma Chemical Co. (St. Louis, MO, USA). Both U0126 and LY294002 were provided by Calbiochem (San Diego, CA, USA). Primary antibodies against HO-1, ERK, phospho ERK, Nrf2, and $\beta$-actin were purchased from Santa Cruz Biotechnology, Inc. (Santa Cruz, CA, USA). The primary Akt and phospho Akt (Ser 473) antibodies were purchased from Cell Signaling Technology (Beverly, MA, USA). Rabbit polyclonal antibody specific for phospho Nrf2 was purchased from Epitomics, Inc. (Burlingame, CA, USA). Any other chemicals and reagents were of analytical grade.

Cell culture. Human keratinocytes (HaCaT cells) were obtained from Amore Pacific (Gyeonggi-do, Republic of Korea). Cells were cultured in Dulbecco's modified Eagle's medium containing $10 \%$ heat-inactivated fetal calf serum, streptomycin $(100 \mu \mathrm{g} / \mathrm{ml})$, and penicillin $(100 \mathrm{U} / \mathrm{ml})$. The cells were maintained at $37^{\circ} \mathrm{C}$ in an incubator with a humidified atmosphere of $5 \% \mathrm{CO}_{2}$.

Reverse transcriptase-polymerase chain reaction (RT-PCR). Cells $\left(3 \times 10^{6}\right.$ cells $\left./ \mathrm{ml}\right)$ were seeded into $100-\mathrm{mm}$ culture dish. Sixteen hours later, the cells were treated with DHF at concentrations of $0.5,1,5,10$, or $20 \mu \mathrm{g} / \mathrm{ml}$. The cells were collected at the indicated times and washed twice with phosphate-buffered saline (PBS). Total RNA was isolated from the cells using TRIzol ${ }^{\circledR}$ reagent (Gibco-BRL, Grand Island, NY, USA). RT-PCR conditions for HO-1 and the housekeeping gene, glyceraldehyde 3-phosphate dehydrogenase (GAPDH), were as follows: 35 cycles of $94^{\circ} \mathrm{C}$ for $45 \mathrm{sec} ; 53^{\circ} \mathrm{C}$ for $45 \mathrm{sec}$; and $72^{\circ} \mathrm{C}$ for $60 \mathrm{sec}$. The primer pairs (Bionics, Seoul, Republic of Korea) used were: HO-1, forward: 5'-GAGAATGCTGAGTTCATG-3' and reverse: 5'-ATGTTGAGCAGGAAGGC-3'; GAPDH, forward: 5'-GTGGGCCGCCCTAGGCACCAGG-3' and reverse: 5'-GGAGGAAGAGGATGCGGCAGTG-3'. Amplified products were resolved on $1 \%$ agarose gels, stained with ethidium bromide, and images were captured under ultraviolet light.

HO-1 activity assay. HO-1 enzyme activity was measured as previously described (23). Briefly, cells were homogenized in $0.5 \mathrm{ml}$ ice-cold $0.25 \mathrm{M}$ sucrose solution containing $50 \mathrm{mM}$ potassium phosphate buffer ( $\mathrm{pH}$ 7.4). Homogenates were centrifuged at $200 \mathrm{x} g$ for $10 \mathrm{~min}$. Supernatants were centrifuged at $9000 \times \mathrm{g}$ for $20 \mathrm{~min}$, and then centrifuged at $15,000 \mathrm{x} \mathrm{g}$ for $60 \mathrm{~min}$. The resulting pellet (cell lysate) was resuspended in $50 \mathrm{mM}$ potassium phosphate buffer ( $\mathrm{pH} 7.4)$, and the amount of protein in the cell lysate was determined.

A reaction mixture $(200 \mu \mathrm{l})$ containing $500 \mu \mathrm{g} / \mathrm{ml}$ cell lysate, $0.2 \mathrm{mM}$ hemin, $0.5 \mathrm{mg} / \mathrm{ml}$ rat liver cytosol as the source of biliverdin reductase, $0.2 \mathrm{mM} \mathrm{MgCl}, 2 \mathrm{mM}$ glucose- 6 -phosphate, $1 \mathrm{U} / \mathrm{ml}$ glucose-6-phosphate dehydrogenase, $1 \mathrm{mM}$ $\mathrm{NADPH}$, and $50 \mathrm{mM}$ potassium phosphate buffer $(\mathrm{pH} 7.4)$ was incubated at $37^{\circ} \mathrm{C}$ for $1 \mathrm{~h}$. The reaction was stopped with chloroform $(0.5 \mathrm{ml})$. Following extraction, the chloroform layer was measured spectrophotometrically. Bilirubin formation from the hemin substrate was calculated according to the difference in absorption at 464 and $530 \mathrm{~nm}$.

Western blot analysis. Cells $\left(3 \times 10^{6}\right.$ cells $\left./ \mathrm{ml}\right)$ were seeded into a $100-\mathrm{mm}$ culture dish. Sixteen hours later, the cells were treated with DHF (5 $\mu \mathrm{g} / \mathrm{ml})$, collected at the indicated times and washed twice with PBS. The collected cells were lysed on ice for $30 \mathrm{~min}$ in $100 \mu \mathrm{l}$ lysis buffer $[120 \mathrm{mM} \mathrm{NaCl}, 40 \mathrm{mM}$ Tris ( $\mathrm{pH} 8.0$ ), and $0.1 \% \mathrm{NP} 40$ ] and centrifuged at $13,000 \mathrm{x} \mathrm{g}$ for $15 \mathrm{~min}$. Supernatants were collected from the lysates, and protein concentrations of the supernatants were determined. Aliquots of the lysates ( $40 \mu \mathrm{g}$ protein) were boiled for $5 \mathrm{~min}$ and electrophoresed on $10 \%$ sodium dodecyl sulfate polyacrylamide gels. Electrophoresed proteins were transferred onto nitrocellulose membranes (Bio-Rad, Hercules, CA, USA), which were incubated with primary antibodies. Membranes were then incubated with horseradish peroxidase-conjugated secondary antibodies (Pierce, Rockland, IL, USA) and images were captured with LAS-3000 (Fujifilm Corp., Tokyo, Japan). Protein bands were detected using an enhanced chemiluminescence Western blot detection kit (Amersham, Little Chalfont, UK).

Preparation of nuclear extracts. The cells were collected at the indicated times and lysed on ice in $1 \mathrm{ml}$ lysis buffer [10 mM Tris- $\mathrm{HCl}$ (pH 7.9), $10 \mathrm{mM} \mathrm{NaCl}, 3 \mathrm{mM} \mathrm{MgCl}_{2}$, and $1 \% \mathrm{NP}-40$ ] for $4 \mathrm{~min}$. Following centrifugation at 3,000 $\mathrm{x} \mathrm{g}$ for $10 \mathrm{~min}$, the pellets were resuspended in $50 \mu \mathrm{l}$ extraction buffer [20 mM HEPES (pH 7.9), 20\% glycerol, $1.5 \mathrm{mM} \mathrm{MgCl}_{2}$, $300 \mathrm{mM} \mathrm{NaCl}, 0.2 \mathrm{mM}$ EDTA, $1 \mathrm{mM}$ DTT, and $1 \mathrm{mM}$ PMSF], incubated on ice for $30 \mathrm{~min}$, and centrifuged at 13,000 $\mathrm{x} \mathrm{g}$ for $5 \mathrm{~min}$. Supernatants were collected and stored at $-70^{\circ} \mathrm{C}$ after measurement of the protein concentration.

Immunocytochemistry. Cells were plated on coverslips, fixed with $4 \%$ paraformaldehyde for $30 \mathrm{~min}$, and permeabilized with PBS containing 0.1\% Triton X-100 for $2.5 \mathrm{~min}$. The cells were then treated with blocking medium (PBS containing $3 \%$ bovine serum albumin) for $1 \mathrm{~h}$ and incubated with a primary anti-Nrf2 antibody diluted in blocking medium for $2 \mathrm{~h}$. The immunoreacted primary antibody was detected by incubating cells with a fluorescein isothiocyanate (FITC)-conjugated secondary antibody (1:500 dilution) (Jackson ImmunoResearch Laboratories, West Grove, PA, USA) for $1 \mathrm{~h}$. After washing with PBS, stained cells were mounted onto microscope slides in mounting medium containing DAPI to label nuclei (Vector, Burlingame, CA, USA). Images were collected using a Zeiss confocal microscope and Zeiss LSM 510 software. 
Chromatin immunoprecipitation (ChIP). The ChIP assay was performed with a Simple ChIP ${ }^{\mathrm{TM}}$ enzymatic chromatin IP kit (Cell Signaling Technology, Danvers, MA, USA) according to the manufacturer's instructions, with slight modifications. Briefly, cellular proteins were crosslinked by the addition of $1 \%$ formaldehyde. Prepared chromatin was digested using a nuclease for $12 \mathrm{~min}$ at $37^{\circ} \mathrm{C}$. A primary anti-Nrf2 antibody and normal rabbit IgG were added to the chromatin digest, and the mixture was incubated with constant rotation overnight at $4^{\circ} \mathrm{C}$. To capture the immunoprecipitated complexes, ChIP-grade protein $\mathrm{G}$ magnetic beads were added. The beads were washed, and the immunoprecipitate was eluted with ChIP elution buffer. Crosslinking was reversed by incubating the eluent at $65^{\circ} \mathrm{C}$ for $30 \mathrm{~min}$, followed by the addition of proteinase $\mathrm{K}$ and incubation at $65^{\circ} \mathrm{C}$ for $2 \mathrm{~h}$. The immunoprecipitated DNA fragments were purified on spin columns. DNA recovered from the immunoprecipitated complexes was subjected to 35 cycles of PCR. The primers for the HO-1 gene promoter were: forward: 5'-CCAGAAAGTGGGCATCAGCT-3' and reverse: 5'-GTCACATTTATGCTCGGCGG-3'. PCR products were resolved on $1 \%$ agarose gels, and DNA bands were visualized using ethidium bromide staining and images were captured under ultraviolet light.

Cell viability assay. The effect of DHF on cell viability was determined using the MTT assay, which is based on the reduction of a tetrazolium salt by a mitochondrial dehydrogenase in viable cells (24). Cells were seeded in a 96-well plate at a density of $3 \times 10^{5}$ cells $/ \mathrm{ml}$ and treated for $2 \mathrm{~h}$ with $5 \mu \mathrm{g} / \mathrm{ml}$ DHF, $10 \mu \mathrm{M}$ ZnPP (an inhibitor of HO-1), $10 \mathrm{nM}$ U0126 (an inhibitor of ERK kinase), and $5 \mu \mathrm{M} \mathrm{LY} 294002$ (an inhibitor of PI3K), followed by $1 \mathrm{mM} \mathrm{H} \mathrm{O}_{2}$ or $30 \mathrm{~mJ} / \mathrm{cm}^{2} \mathrm{UVB}$ for $1 \mathrm{~h}$. After incubation for $24 \mathrm{~h}$ at $37^{\circ} \mathrm{C}, 50 \mu 1$ MTT stock solution ( $2 \mathrm{mg} / \mathrm{ml}$ ) was added to each well to achieve a total reaction volume of $250 \mu \mathrm{l}$. After incubation for $2.5 \mathrm{~h}$, the supernatants were aspirated. The formazan crystals in each well were dissolved in $150 \mu \mathrm{l}$ dimethyl sulfoxide, and the absorbance at $540 \mathrm{~nm}$ was read on a scanning multi-well spectrophotometer.

Statistical analysis. Values are given as the mean \pm standard error of the mean (SEM). The results were subjected to an analysis of variance (ANOVA) followed by the Tukey's test to analyze differences between conditions. $\mathrm{P}<0.05$ was considered to indicate statistical significance.

\section{Results}

DHF induces HO-1 mRNA levels and activity. DHF at concentrations of $0.5,1$ and $5 \mathrm{mg} / \mathrm{ml}$ dose-dependently increased HO-1 mRNA levels in HaCaT cells, while DHF at concentrations of 10 and $20 \mathrm{mg} / \mathrm{ml}$ slightly decreased mRNA levels relative to the level induced by $5 \mathrm{mg} / \mathrm{ml}$ DHF (Fig. 1A). Furthermore, DHF $(0.5,1$, and $5 \mathrm{mg} / \mathrm{ml})$ dose-dependently increased HO-1 activity, with a clear effect at $5 \mathrm{mg} / \mathrm{ml}$ (Fig. 1B). When cell viability was assessed by the MTT assay, DHF did not show any cytotoxicity at $0.5,1$, or $5 \mathrm{mg} / \mathrm{ml}$ (data not shown). From these results, $5 \mathrm{mg} / \mathrm{ml}$ DHF was selected as the optimal concentration for subsequent experiments. DHF $(5 \mathrm{mg} / \mathrm{ml})$ enhanced HO-1 mRNA and protein expression in a time-dependent manner (Fig. 1C and D). The time course for the elevated HO-1
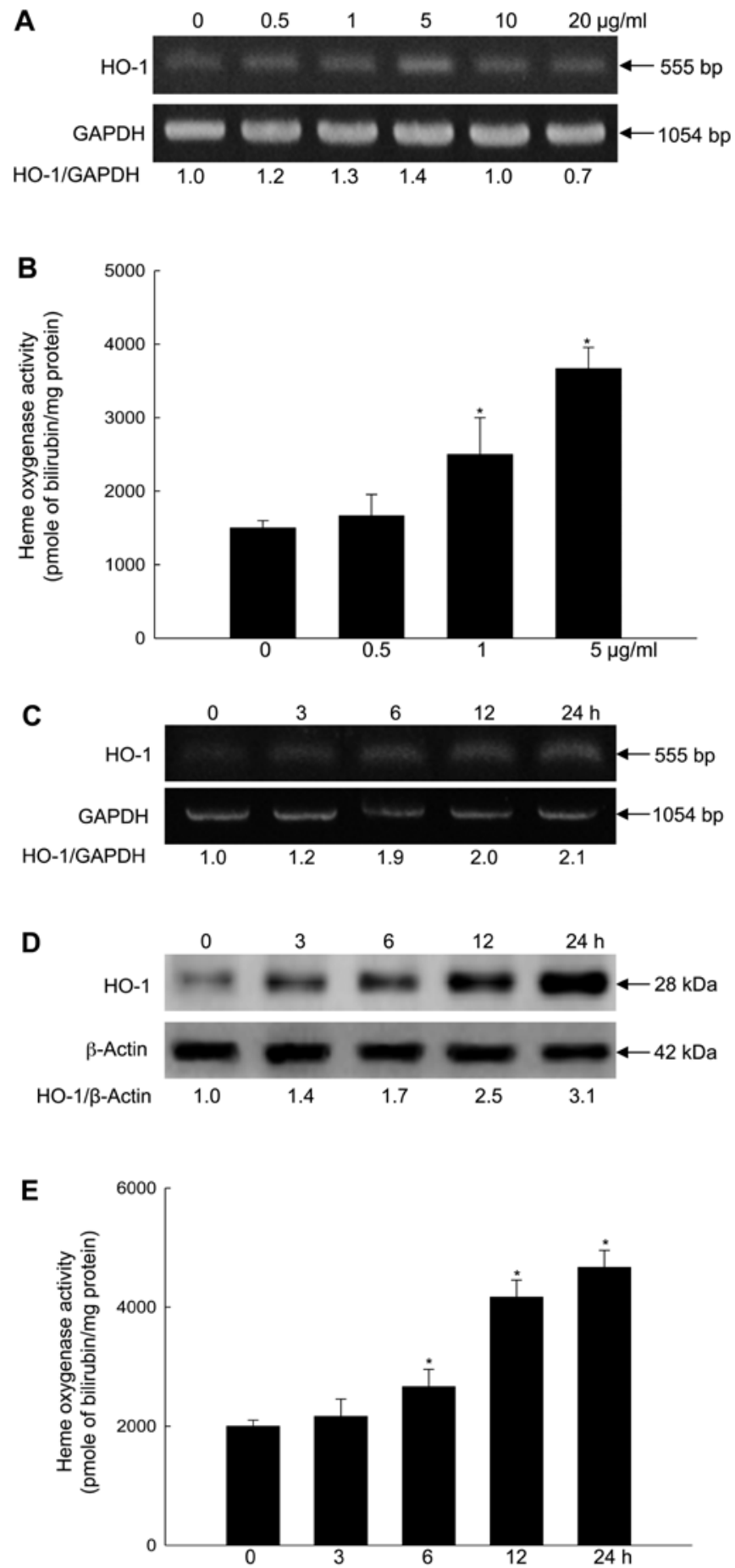

Figure 1. Effect of DHF treatment on the expression and activity of HO-1. Cells were treated with various concentrations of DHF for $24 \mathrm{~h}$ (A and B) or with $5 \mu \mathrm{g} / \mathrm{ml}$ DHF for various periods of time (C-E). (A and C) HO-1 mRNA expression was analyzed by RT-PCR. HO-1 mRNA levels were normalized to GAPDH mRNA levels. (B and E) HO-1 activity was determined by measuring the amount of bilirubin formed. Bars show the mean \pm SEM. Significantly different from control $\left({ }^{*} \mathrm{P}<0.05\right)$. (D) HO-1 protein expression was analyzed by subjecting cell lysates to western blotting with an anti-HO-1 primary antibody.

expression was closely correlated with that for the increased HO-1 activity (Fig. 1E).

DHF induces $\mathrm{Nrf} 2$ expression, nuclear translocation and binding to ARE. Nrf2 is a redox-sensitive basic-leucine zipper 
A

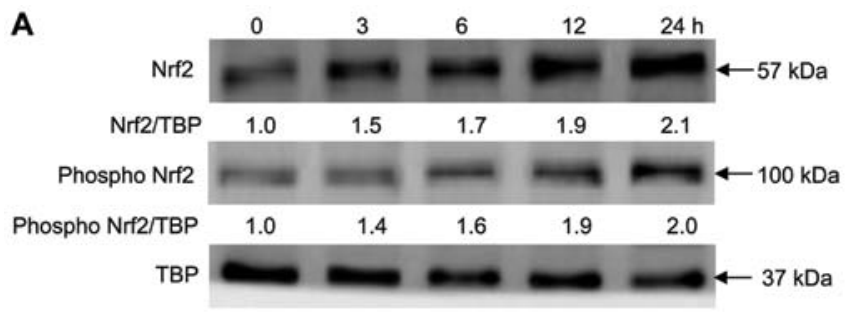

B

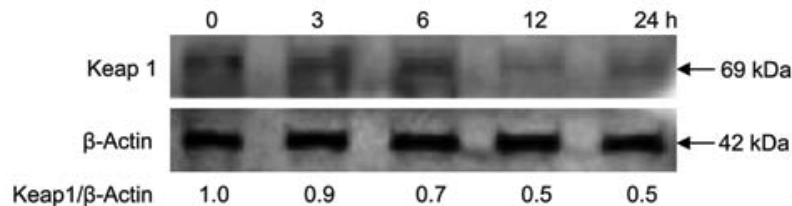

C
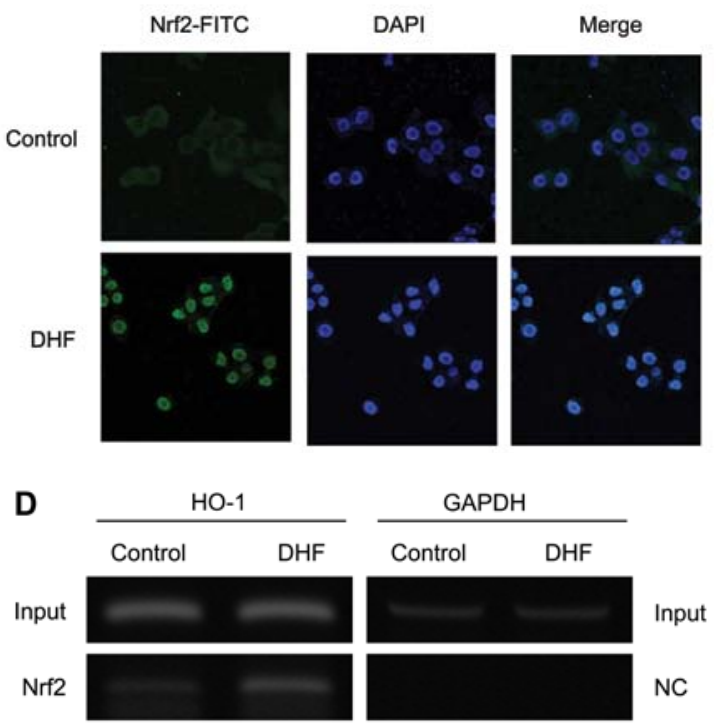

Figure 2. Effect of DHF treatment on Nrf2 expression, phosphorylation, nuclear translocation, and binding to the HO-1 gene promoter. (A) Nrf2 and phospho-Nrf2 levels were analyzed by subjecting nuclear extracts to western blotting with anti-Nrf2 and anti-phospho Nrf2 antibodies. Protein levels were normalized to TATA binding protein (TBP) levels. (B) Keap1 expression was analyzed by subjecting cell lysates to western blotting with an antiKeap1 antibody. Keap1 levels were normalized to $\beta$-actin levels. (C) Nrf2 was labeled with an anti-Nfr2 antibody and a FITC-conjugated secondary antibody (green) and cells were observed using confocal microscopy. DAPI staining indicates the location of nuclei (blue). Merged images illustrate that nuclear translocation of Nrf2 is enhanced in DHF-treated cells in comparison to control cells. (D) Nrf2 binding to the ARE sequence of the HO-1 promoter was analyzed using the ChIP assay followed by PCR.

transcription factor. Its activity is blocked by Keap1, a negative regulator of Nrf2 that forms a complex with the transcription factor in the cytoplasm and prevents its phosphorylation and translocation into the nucleus (14). Protein levels of total nuclear and phosphorylated Nrf2 (phospho Nrf2) were increased in a time-dependent manner by DHF treatment of $\mathrm{HaCaT}$ cells (Fig. 2A), whereas Keap1 expression was decreased (Fig. 2B). DHF markedly increased the translocation of Nrf2 from the cytosol into the nucleus (Fig. 2C). Moreover, Nrf2 binding to the ARE sequence in the HO-1 promoter region was markedly higher in DHF-treated cells than in untreated cells, as assessed by the ChIP assay (Fig. 2D).
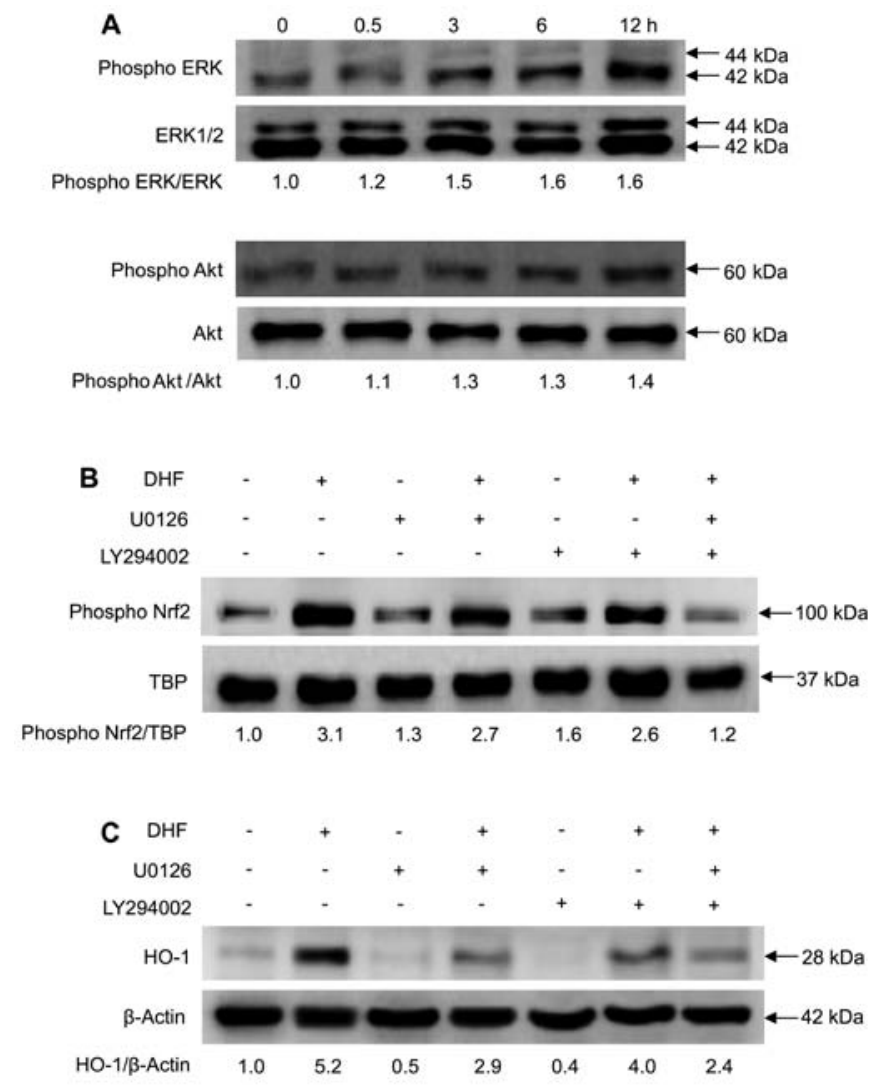

Figure 3. Effect of DHF treatment on the ERK and PI3K/Akt signaling pathways. (A) Cells were treated with DHF, and total protein lysates were analyzed by western blotting with ERK, -phospho ERK, -Akt and -phospho Akt antibodies. After treatment with U0126 and DHF, or LY294002 and DHF, cell lysates were subjected to western blotting with (B) a phospho-Nrf2 and (C) an HO-1 primary antibody.

DHF activates Nrf2 and increases HO- 1 expression via phosphorylation of ERK and Akt. To investigate the upstream signaling pathways involved in DHF-enhanced Nrf2 activation and HO-1 expression, we examined the phosphorylation of ERK and Akt, which are important signaling enzymes that are involved in cellular protection against oxidative stress $(16,25)$. DHF treatment of keratinocytes increased the phosphorylation of ERK and Akt in a time-dependent manner (Fig. 3A). Moreover, selective inhibitors of ERK (U0126) and Akt (LY294002, which blocks PI3K upstream of Akt) reduced the levels of DHF-induced phospho-Nrf2 (Fig. 3B) and HO-1 (Fig. 3C). These results suggest that DHF increased the levels of phospho-Nrf2 and HO-1 via ERK- and PI3K/Akt-dependent pathways.

Involvement of HO-1 and ERK and Akt pathways in DHF-induced cytoprotection against oxidative stress. To determine whether DHF-enhanced HO-1 activity confers cytoprotection to keratinocytes against oxidative stress, $\mathrm{HaCaT}$ cells were pre-treated with the HO-1 inhibitor $\mathrm{ZnPP}$ and then exposed to $\mathrm{H}_{2} \mathrm{O}_{2}$ or UVB radiation. Cell viability was significantly reduced by $\mathrm{H}_{2} \mathrm{O}_{2}$ or UVB exposure, but not by pre-treatment with DHF or ZnPP alone (Fig. 4A and B). Pre-treatment with DHF prevented $\mathrm{H}_{2} \mathrm{O}_{2}$ and UVB-induced cytotoxicity. ZnPP attenuated the protective effect of DHF against $\mathrm{H}_{2} \mathrm{O}_{2}$ and UVB-induced cellular damage, as assessed 

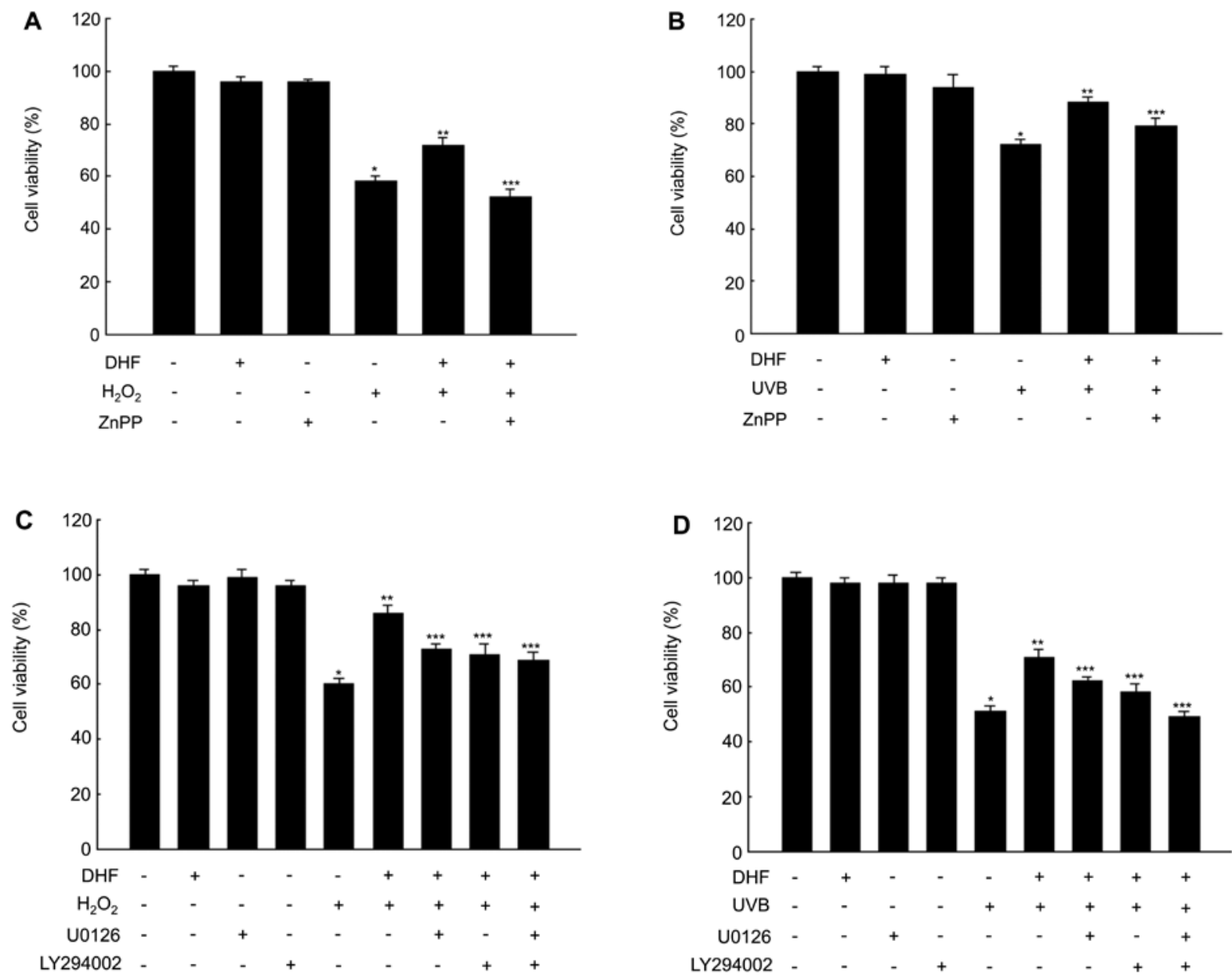

Figure 4. Cytoprotective effect of DHF treatment against oxidative stress. (A) Cells were pre-treated with ZnPP $(1 \mathrm{mM})$ for $1 \mathrm{~h}$, followed by $1 \mathrm{~h}$ incubation with DHF and exposure to (A) $1 \mathrm{mM} \mathrm{H}_{2} \mathrm{O}_{2}$ or (B) UVB radiation. Alternatively, cells were pre-treated with U0126 or LY294002 for $1 \mathrm{~h}$, followed by $1 \mathrm{~h}$ incubation with DHF and exposure to (C) $1 \mathrm{mM} \mathrm{H}_{2} \mathrm{O}_{2}$ or (D) UVB radiation. After $24 \mathrm{~h}$, cell viability was measured using the MTT assay. Significantly different from: control ("P<0.05), $\mathrm{H}_{2} \mathrm{O}_{2}$ - or UVB-treated cells $\left({ }^{* *} \mathrm{P}<0.05\right)$, and DHF $+\mathrm{H}_{2} \mathrm{O}_{2}$ - or DHF + UVB-treated cells $\left({ }^{* * *} \mathrm{P}<0.05\right)$.

by reduced cell viability in the MTT assay (Fig. 4A and B). Therefore, the cytoprotective effect of DHF is likely to be mediated through HO-1 induction.

We also examined whether DHF can mitigate oxidative damage to cells through the activation of ERK and Akt. U0126 and LY294002 reduced the protective effect of DHF against $\mathrm{H}_{2} \mathrm{O}_{2}$ and UVB exposure (Fig. 4C and D), suggesting that ERK and Akt signaling pathways are also involved in DHF-mediated cytoprotection.

\section{Discussion}

The epidermis and its associated cells comprise a critical defense mechanism against oxidative damage. Keratinocytes in particular are constantly exposed to environmental prooxidants. Such exposure leads to harmful effects on the skin (e.g., premature aging and cancer) in the absence of appropriate protective cell responses.

The current study has demonstrated that DHF, a naturally occurring antioxidant, activated HO-1 expression by targeting the ARE sequence within the HO-1 gene promoter region. The DHF-mediated activation of HO-1 was regulated through the stimulation of Nrf2 in an ERK and PI3K/Akt-dependent manner. Findings of previous studies have demonstrated the involvement of ERK and PI3K/Akt in the activation of HO-1 expression and Nrf2-mediated signal transduction (25-27). For example, ERK phosphorylates Nrf2, triggering dissociation of the Keap1-Nrf2 complex and translocation of Nrf2 into the nucleus, where it forms a heterodimer with a small Maf protein (16,28-30). In the present study, DHF treatment increased the levels of phospho-ERK and -PI3K/Akt. In addition, specific inhibitors of the ERK and PI3K/Akt pathways suppressed the nuclear translocation of Nrf2, suggesting that Nrf2 is a direct downstream target of ERK and PI3K/Akt. Thus, ERK and PI3K/Akt may be crucial components of the cellular signaling network responsible for the activation of $\mathrm{Nrf} 2$ and the transcriptional regulation of HO-1 gene expression in keratinocytes.

Similar to DHF, several compounds isolated from natural products induce $\mathrm{HO}-1$ expression via activation of Nrf2 downstream of ERK and/or PI3K/Akt. For instance, eckol (found in brown algae) and (-)-epigallocatechin gallate (found in green tea) increase HO-1 levels by activating ERK, PI3K/Akt and $\mathrm{Nrf} 2(31,32)$. In addition, baicalein (originally isolated from 
the root of Scutellaria baicalensis) prevents oxidative damage in PC12 cells by stimulating the PI3K/Akt/Nrf2 pathway in order to upregulate HO-1 expression (33). Furthermore, DHP exhibited the most potent protective effects as compared with other flavonoids in the neuroprotective area (34).

Under normal physiological conditions, Nrf2 is sequestered in the cytoplasm by Keap1. Following the oxidation of specific cysteine residues within Keap1 by electrophilic agents or ROS, Nrf2 dissociates from its cytoplasmic docking protein and translocates into the nucleus. There, it binds to the promoter regions of several phase II detoxifying enzymes or antioxidant enzymes including HO-1, thereby activating their transcription (35).However, because the half-life of $\mathrm{Nrf} 2$ is very short ( $<10 \mathrm{~min})$, these mechanisms necessitate the stabilization of the Nrf2 protein $(36,37)$.

In our system, DHF treatment decreased Keap1 expression and increased the level and nuclear translocation of Nrf2. These results suggest that DHF may retard Keap1-mediated Nrf2 degradation. Similarly, baicalein increases Keap1 degradation by the proteasome system and prevents the Keap1-mediated inactivation of Nrf2 (33). We also showed that ERK and PI3K inhibitors decreased the DHF-induced accumulation of phospho-Nrf2 through the inhibition of ERK and Akt phosphorylation. This suggests that ERK and PI3K/Akt phosphorylate Nrf2 and facilitate its release from the Keap1-Nrf2 complex, allowing activated Nrf2 to translocate into the nucleus.

In summary, the present results suggest that DHF protects $\mathrm{HaCaT}$ cells against oxidative stress-induced cell damage. DHF exerts its protective functions by i) activating ERK and PI3K/Akt, ii) facilitating the translocation of Nrf2 into the nucleus and its subsequent binding to ARE and iii) upregulating HO-1 expression.

\section{Acknowledgements}

This study was supported by a grant from the Korean Ministry of Knowledge and Economy (R0000445).

\section{References}

1. Ismail NS, Pravda EA, Li D, Shih SC and Dallabrida SM: Angiopoietin-1 reduces $\mathrm{H}(2) \mathrm{O}(2)$-induced increases in reactive oxygen species and oxidative damage to skin cells. J Invest Dermatol 130: 1307-1317, 2010.

2. Okayama Y: Oxidative stress in allergic and inflammatory skin diseases. Curr Drug Targets Inflamm Allergy 4: 517-519, 2005.

3. Black HS: Potential involvement of free radical reactions in ultraviolet light-mediated cutaneous damage. Photochem Photobiol 46: 213-221, 1987

4. Cerutti PA: Prooxidant states and tumor promotion. Science 227: 375-381, 1985

5. Harman D: Free radical theory of aging: an update: increasing the functional life span. Ann NY Acad Sci 1067: 10-21, 2006.

6. Ryter SW, Alam J and Choi AM: Hemeoxygenase-1/carbon monoxide: from basic science to therapeutic applications. Physiol Rev 86: 583-650, 2006.

7. Tenhunen R, Marver HS and Schmid R: The enzymatic conversion of heme to bilirubin by microsomal heme oxygenase. Proc Natl Acad Sci USA 61: 748-755, 1968.

8. Maines MD: Heme oxygenase: function, multiplicity, regulatory mechanisms, and clinical applications. FASEB J 2: 2557-2568, 1988.

9. Ryter SW and Choi AM: Heme oxygenase-1: molecular mechanisms of gene expression in oxygen-related stress. Antioxid Redox Signal 4: 625-632, 2002.
10. Otterbein LE, Soares MP, Yamashita K and Bach FH: Heme oxygenase-1: unleashing the protective properties of heme. Trends Immunol 24: 449-455, 2003.

11. Li MH, Cha YN and Surh YJ: Peroxynitrite induces HO-1 expression via PI3K/Akt-dependent activation of NF-E2-related factor 2 in PC12 cells. Free Radic Biol Med 41: 1079-1091, 2006.

12. Khor TO, Huang MT, Kwon KH, Chan JY, Reddy BS and Kong AN: Nrf2-deficient mice have an increased susceptibility to dextran sulfate sodium-induced colitis. Cancer Res 66: 11580-11584, 2006.

13. Alam J and Cook JL: Transcriptional regulation of the heme oxygenase-1 gene via the stress response element pathway. Curr Pharm Des 9: 2499-2511, 2003.

14. Itoh K, Wakabayashi N, Katoh Y, Ishii T, Igarashi K, Engel JD and Yamamoto M: Keap1 represses nuclear activation of antioxidant responsive elements by Nrf2 through binding to the amino-terminal Neh2 domain. Genes Dev 13: 76-86, 1999.

15. Yu S, Khor TO, Cheung KL, Li W, Wu TY, Huang Y, Foster BA, Kan YW and Kong AN: Nrf2 expression is regulated by epigenetic mechanisms in prostate cancer of TRAMP mice. PLoS One 5: e8579, 2010.

16. Li MH, Jang JH, Na HK, Cha YN and Surh YJ: Carbon monoxide produced by heme oxygenase-1 in response to nitrosative stress induces expression of glutamate-cysteine ligase in PC 12 cells via activation of phosphatidylinositol 3-kinase and Nrf2 signaling. J Biol Chem 282: 28577-28586, 2007.

17. Yu R, Chen C, Mo YY, Hebbar V, Owuor ED, Tan TH and Kong AN: Activation of mitogen-activated protein kinase pathways induces antioxidant response element-mediated gene expression via a Nrf2-dependent mechanism. J Biol Chem 275: 39907-39913, 2000.

18. Silva MM, Santos MR, Caroco G, Rocha R, Justino G and Mira L: Structure-antioxidant activity relationships of flavonoids: a re-examination. Free Radic Res 36: 1219-1227, 2002.

19. Melidou M, Riganakos K and Galaris D: Protection against nuclear DNA damage offered by flavonoids in cells exposed to hydrogen peroxide: the role of iron chelation. Free Radic Biol Med 39: 1591-1600, 2005.

20. Williams RJ, Spencer JP and Rice-Evans C: Flavonoids: antioxidants or signaling molecules? Free Radic Biol Med 36: 838-849, 2004

21. Moridani MY, Pourahmad J, Bui H, Siraki A and O'Brien PJ: Dietary flavonoid iron complexes as cytoprotective superoxide radical scavengers. Free Radic Biol Med 34: 243-253, 2003.

22. Zhang R, Kang KA, Piao MJ, Ko DO, Wang ZH, Chang WY, You HJ, Lee IK, Kim BJ, Kang SS and Hyun JW: Preventive effect of 7,8-dihydroxyflavone against oxidative stress-induced genotoxicity. Biol Pharm Bull 32: 166-171, 2009.

23. Kutty RK and Maines MO: Oxidation of heme $\mathrm{c}$ derivatives by purified heme oxygenase. Evidence for the presence of one molecular species of heme oxygenase in the rat liver. J Biol Chem 257: 9944-9952, 1982

24. Carmichael J, DeGraff WG, Gazdar AF, Minna JD and Mtchell JB: Evaluation of a tetrazolium-based semiautomated colorimetric assay: assessment of chemosensitivity testing. Cancer Res 47: 936-942, 1987.

25. Cullinan SB and Diehl JA: PERK-dependent activation of Nrf2 contributes to redox homeostasis and cell survival following endoplasmic reticulum stress. J Biol Chem 279: 20108-20117, 2004.

26. Bloom DA and Jaiswal AK: Phosphorylation of Nrf2 at Ser40 by protein kinase $\mathrm{C}$ in response to antioxidants leads to the release of Nrf2 from INrf2, but is not required for Nrf2 stabilization/accumulation in the nucleus and transcriptional activation of antioxidant response element-mediated NAD $(\mathrm{P}) \mathrm{H}$ : quinone oxidoreductase-1 gene expression. J Biol Chem 278: 44675-44682, 2003.

27. Hwang YP and Jeong HG: Ginsenoside Rb1 protects against 6-hydroxydopamine-induced oxidative stress by increasing heme oxygenase-1 expression through an estrogen receptor-related $\mathrm{PI} 3 \mathrm{~K} / \mathrm{Akt} / \mathrm{Nrf} 2$-dependent pathway in human dopaminergic cell. Toxicol Appl Pharmacol 242: 18-28, 2010.

28. Chan K, Han XD and Kan YW: An important function of Nrf2 in combating oxidative stress: detoxification of acetaminophen. Proc Natl Acad Sci USA 98: 4611-4616, 2001.

29. Kim YC, Masutani H, Yamaguchi Y, Itoh K, Yamamoto M and Yodoi J: Hemin-induced activation of the thioredoxin gene by Nrf2. A differential regulation of the antioxidant responsive element by a switch of its binding factors. J Biol Chem 276: 18399-18406, 2001. 
30. Kwak MK, Itoh K, Yamamoto M and Kensler TW: Enhanced expression of the transcription factor Nrf2 by cancer chemopreventive agents: role of antioxidant response element-like sequences in the nrf2 promoter. Mol Cell Biol 22: 2883-2892, 2002.

31. Na HK, Kim EH, Jung JH, Lee HH, Hyun JW and Surh YJ: (-)-Epigallocatechin gallate induces Nrf2-mediated antioxidant enzyme expression via activation of PI3K and ERK in human mammary epithelial cells. Arch Biochem Biophys 476: 171-177, 2008.

32. Kim KC, Kang KA, Zhang R, Piao MJ, Kim GY, Kang MY, Lee SJ, Lee NH, Surh YJ and Hyun JW: Up-regulation of Nrf2mediated heme oxygenase-1 expression by eckol, a phlorotannin compound, through activation of Erk and PI3K/Akt. Int J Biochem Cell Biol 42: 297-305, 2010.

33. Zhang Z, Cui W, Li G, Yuan S, Xu D, Hoi MP, Lin Z, Dou J, Han Y and Lee SM: Baicalein protects against 6-OHDAinduced neurotoxicity through activation of Keap1/Nrf2/HO-1 and involving PKC $\alpha$ and PI3K/AKT signaling pathways. J Agric Food Chem 60: 8171-8182, 2012.
34. Jang SW, Liu X, Yepes M, Shepherd KR, Miller GW, Liu Y, Wilson WD, Xiao G, Blanchi B, Sun YE and Ye K: A selective TrkB agonist with potent neurotrophic activities by 7,8-dihydroxyflavone. Proc Natl Acad Sci USA 107: 2687-2692, 2010.

35. Kobayashi M and Yamamoto M: Molecular mechanisms activating the Nrf2-Keap1 pathway of antioxidant gene regulation. Antioxid Redox Signal 7: 385-394, 2005.

36. Jain AK, Mahajan S and Jaiswal AK: Phosphorylation and dephosphorylation of tyrosine 141 regulate stability and degradation of INrf2: a novel mechanism in Nrf2 activation. J Biol Chem 283: 17712-17720, 2008.

37. Lee OH, Jain AK, Papusha V and Jaiswal AK: An auto-regulatory loop between stress sensors INrf 2 and Nrf2 controls their cellular abundance. J Biol Chem 282: 36412-36420, 2007. 